\title{
Biomedical Informatics and the Convergence of Nano-Bio-Info-Cogno (NBIC) Technologies
}

\author{
F. Martin-Sanchez' V. Maojo² \\ 'Medical Bioinformatics Dept., Institute of Health Carlos III, Ministry of Science and Innovation, \\ Madrid, Spain \\ ${ }^{2}$ Biomedical Informatics Group, Departamento de Inteligencia Artificial, Facultad de Informatica, \\ Universidad Politecnica de Madrid, Madrid, Spain
}

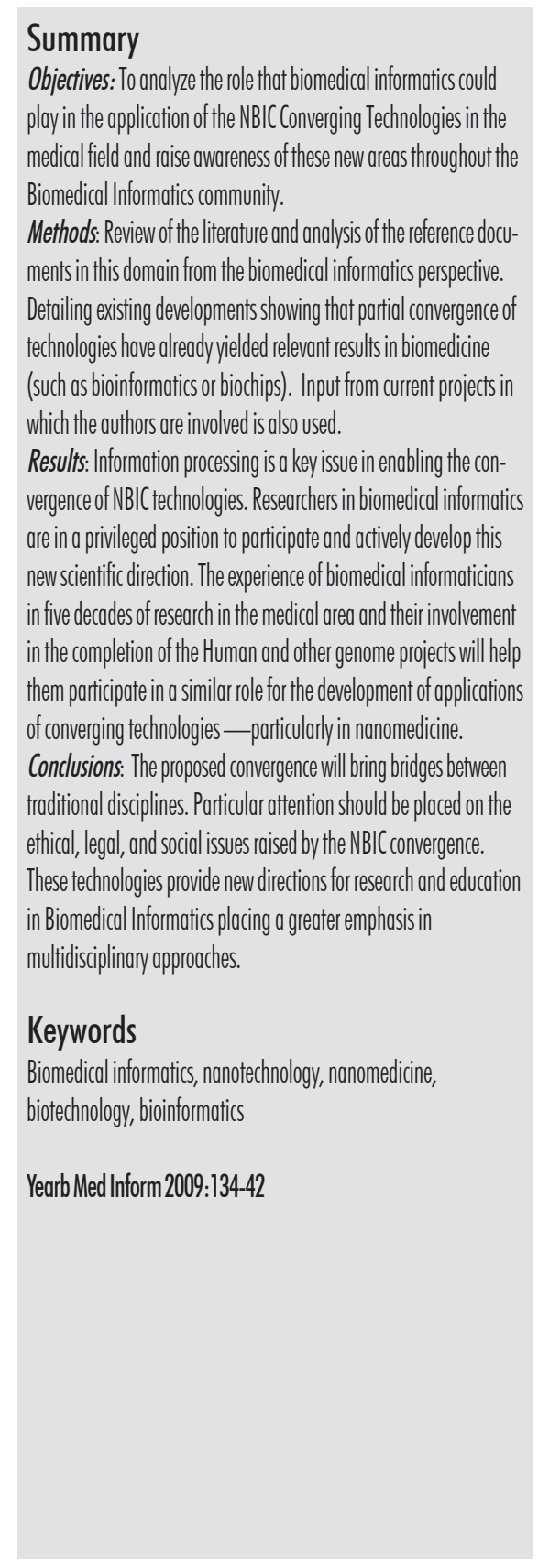

\section{Introduction - The Concept of Converging Technologies}

The beginning of the 21st century has seen increased interest in "Converging Technologies" or NBIC (Nano-BioInfo-Cogno), both from the scientific and research policy worlds. Human society has been characterized as advancing through two different waves (agricultural, industrial), with a third wave leading to the present Age of Information [1]. Following this schema, several authors and reference institutions have already identified a new wave consisting of the convergence of Information and Communication Technologies (ICT) with Biotechnology, another mature cross-discipline that will be strongly developed in the XXI Century. This wave has been referred to as the Era of Transitions [2], or as the Global Technology Revolution [3] -if nanotechnology is also included. All these advances set the scene for the onset of the NBIC converging technologies. The earliest formal definition of this term was published in an NSF document from 2002 "The phrase 'converging technologies' refers to the synergistic combination of four major 'NBIC' (nano-bio-info-cogno) provinces of science and technology, each of which is currently progressing at a rapid rate: (a) nanoscience and nanotechnology;(b) biotechnology and biomedicine, including genetic engineering; (c) information technology, including advanced computing and communications; (d) cognitive science, including cognitive neuroscience" [4]. Other definitions have been published since, such as the one by the Science and Technology Foresight Pilot Project from Canada in its reference document "Bio-Systemics Synthesis" published in 2003 [5]. The European Commission High Level Expert Group "Foresighting the New Technology Wave" in 2004 defined the concept of Converging Technologies as: "enabling technologies and knowledge systems that enable each other in the pursuit of a common goal" [6]. More recently the EU-funded NBIC Knowledge [7] project has extended the definition: "NBIC Converging Technologies aim to be the interdisciplinary study of interactions between living and artificial systems in different scales (nanomacro) for the design of artifacts that improve or expand human cognitive and communicative capabilities, health and social well-being".

All the previous definitions highlight the importance of the synergy between different scientific and technological fields. As the Report by the STOA [8] mentions: "Individually, each of them has a large potential to change society and mankind, but combined they represent a still more powerful source for even bigger change". The European document, entitled "Converging Technologies-Shaping the Future of European Societies (Nano-Bio-InfoCogno-Socio-Anthro-Philo)", identifies Converging Technologies as the greatest research initiative of the $21 \mathrm{st}$ Century. Since then, many other research policies have declared the NBIC convergence as a key issue for the fu- 
ture with applications in many different areas. Health and education are among the fields in which a greater economic and social impact is expected in the short term basis [9]. NBIC has introduced various long-term objectives in medicine, related to research areas such as nanodevices for image processing and navigation within the human body, nanosurgery, virtual simulations of human physiology, nanobiosensors, and others [10]. Some of the main technological developments that act as enablers for the convergence of technologies in medicine are detailed in Table 1. All these forces which drive new trends and innovation often take place on the boundaries between previously different fields [12].

When a research or educational activity receives input from at least two different scientific disciplines it is commonly said that to be pluridisciplinary or multidisciplinary, terms applied to the loose and a priori union between the disciplines, whilst the term interdisciplinary is used for a stronger union with some overlap and integration between the disciplines [13]. In the case of NBIC Converging technologies, as members of one recent European Project state: "At the core of this new concept are relations, synergies or fusions between broad fields of research and development, (the NBIC quartet)" [14].

We can, at this point, ask ourselves whether we are close to this envisioned stage of integration between the four disciplines, represented in Figure 1. The main aspect that would support such a union would be the convergence of all the basic constituent elements (bits, genes, atoms, neurons) at the nano scale. However, we are very far from understanding fundamental phenomena at this level. For example, at this point in time we do not know exactly which physical-chemical processes take place in the development of many tumors and we still cannot predict its dynamics and evolution. The integration of the "cogno" branch seems to be even further away, bearing in mind all the gaps that we have in our knowledge of
Table 1 Driving forces for the convergence of NBIC technologies in Health. Adapted from [11]

\begin{tabular}{|c|c|}
\hline Driving force & Description \\
\hline $\begin{array}{l}\text { - Development of nanotechnology and } \\
\text { trends to miniaturization }\end{array}$ & $\begin{array}{l}\text { - Only in these last years we can get closer, through nanotechnology, to a vision in } \\
\text { which atoms and molecules interact according to the same laws, both in living } \\
\text { and in digital or artificial systems. }\end{array}$ \\
\hline - Exponential growth of processing and using & $\begin{array}{l}\text { - High-throughput laboratory methods such as genomics, proteomics, } \\
\text { metabolomics, molecular imaging. }\end{array}$ \\
\hline $\begin{array}{l}\text { - Consideration of cells and brain as } \\
\text { information processors }\end{array}$ & - Advances in computational biology, systems biology, neuroinformatics. \\
\hline $\begin{array}{l}\text { - Increasing time and cost in the } \\
\text { development of new drugs }\end{array}$ & $\begin{array}{l}\text { - Pharmaceutical industry searches for new more effective and secure methods for } \\
\text { the design, development, assay, prescription and drug delivery. }\end{array}$ \\
\hline - Trend towards personalized medicine & $\begin{array}{l}\text { - The development of genomics and cellular therapies offer the possibility of } \\
\text { developing diagnostic and therapeutic systems, better adapted to human } \\
\text { variation }\end{array}$ \\
\hline $\begin{array}{l}\text { - Availability of research staff already } \\
\text { trained in at least two areas }\end{array}$ & $\begin{array}{l}\text { - Some educational programs and research experiences have already created } \\
\text { working communities already trained in at least two converging technologies } \\
\text { (bioinformatics, neuroinformatics, nanomedicine). }\end{array}$ \\
\hline $\begin{array}{l}\text { - Maturity of the industry of medical devices } \\
\text { (diagnostics, image) }\end{array}$ & $\begin{array}{l}\text { - There are businesses capable of developing and integrating new diagnostic } \\
\text { systems both image based (molecular and functional imaging) and miniaturized } \\
\text { analytical devices (labchips) }\end{array}$ \\
\hline $\begin{array}{l}\text { - Existence of several successful cases such } \\
\text { as biochips }\end{array}$ & $\begin{array}{l}\text { - Biochips represent a clear example of the convergence of technologies } \\
\text { (biotechnology and electronics) widely use now a days in biomedical research for } \\
\text { analyzing molecular processes in cells and tissues. }\end{array}$ \\
\hline $\begin{array}{l}\text { - Existence of a culture of liaisons between } \\
\text { companies and cooperative research in the } \\
\text { academic environment }\end{array}$ & $\begin{array}{l}\text { - Technological companies are less reluctant to establish liaisons for the } \\
\text { development of technologies and knowledge production. Also new trends in } \\
\text { research funding, in Europe that facilitate the development of large collaborative } \\
\text { networks and virtual research centers }\end{array}$ \\
\hline
\end{tabular}

\section{NEW APPLICATIONS IN MEDICINE}
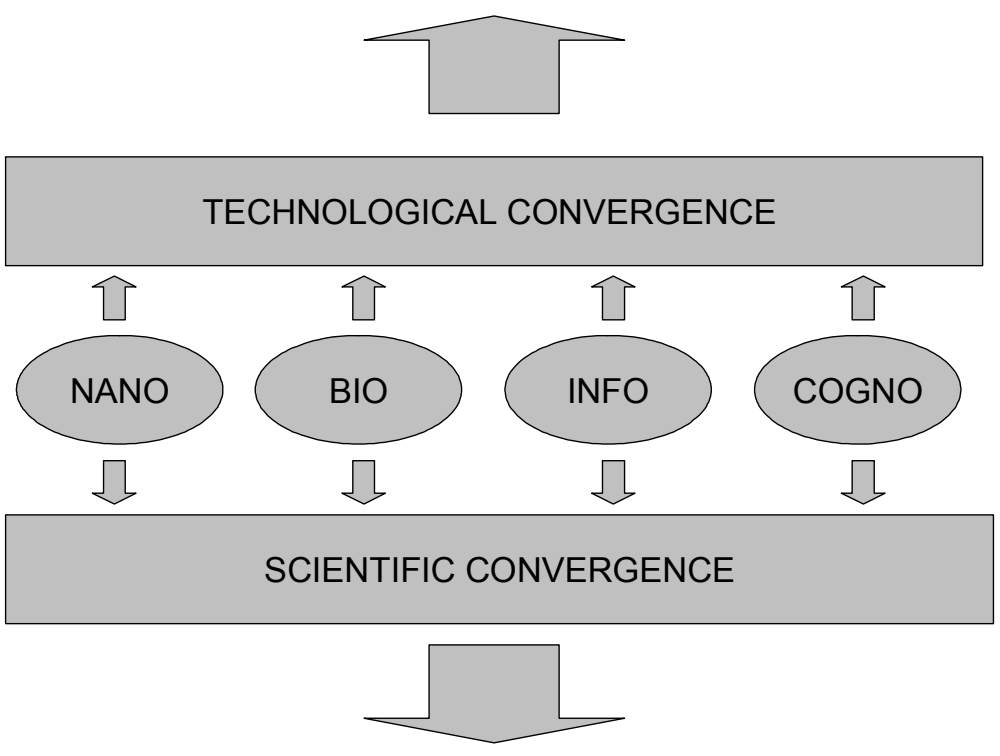

\section{ADVANCES IN BIOMEDICAL SCIENCE}

Fig. 1 Scientific convergence based on the cooperation and cross-fertilisation of different scientific disciplines, trying to answer a common question. Technological convergence, meaning the use of the findings from different disciplines in specific applications and technological products. 
the structure and function of the nervous system. It is with all this in mind that it might be more appropriate to adopt dual, parallel routes: we can advance in the partial convergence of the more mature technologies (BIO+INFO, NANO+INFO) while at the same time new knowledge on the other branches can be integrated as it is produced. It is important not to forget the philosophical debate needed to overcome the existing barriers to achieve interdisciplinarity, taking into account similarities and differences between the two disciplines.

\section{Examples of Technological Convergence and their Appli- cations in Medicine}

After a thorough review of the available literature, it seems that there are not too many examples of an actual convergence between the four fields. But there is enough evidence of advances due to the convergence of Information Technologies involving one or two of the other technologies (BIO, NANO). In fact, some research at the intersection has been successfully carried out for medical uses (such as bioinformatics or biosensors). Interestingly enough many researchers working in these converging areas do not recognize their work as being part of the NBIC complex, which suggests a lack of awareness of this important and broader scientific research context in the scientific community in general. In this section we will identify and detail several of these examples of partial convergence and briefly describe their use in medicine.

\subsection{Info-Bio Convergence}

The convergence of Biotechnology and Information Technology started decades ago. Nevertheless, only recently a renewed interest in this convergence has appeared following the completion of the Human Genome Project. The rise of a Genomic Era and the increasing processing and storage capabilities of computers have accelerated this trend. The workshop "BIONICS - Bio-Inspired Information Technologies", held in Brussels in June 2001, explored the possibilities of a joint EU-US research agenda in the field of bio-inspired information technology [15]. In December 2001, the European Commission (EC) organized a scientific meeting called "Synergy between Research in Medical Informatics, Bio-Informatics and Neuro-Informatics: Knowledge empowering Individualized Healthcare and Well-Being" that explored the convergence of these disciplines in the framework of personalized medicine [16]. This was the start of the BIOINFOMED study [17] that delivered a White Paper addressing the synergy between Medical Informatics and Bioinformatics and proposed a European research agenda in Biomedical Informatics (BMI) for personalized medicine. Along this direction, in Oc- tober 2004, the EC organized another Workshop named "ICT at the Crossroads with Life Sciences". Its main objective was to carry out a scientific debate on the visions and challenges that lie at the crossroads of ICT and Life Sciences, and identify a research agenda that could inform the European Commission about potential areas to be addressed in future ICT Calls for Projects. The focus was on multidisciplinary approaches between the different fields taking into account their potential impact in the area of health and well-being [18]. One year later, an EC funded project, named Beyond the Horizon, studied the convergence between INFO and BIO from the opposite perspective. It focused on the analysis of biological models and behaviors that could serve as inspiration for the next generation of computer systems (Bio-inspired computing) [19]. These different directions for convergence are shown in Figure 2. Examples of the results of the INFO-BIO convergence in both directions are shown in table 2 .

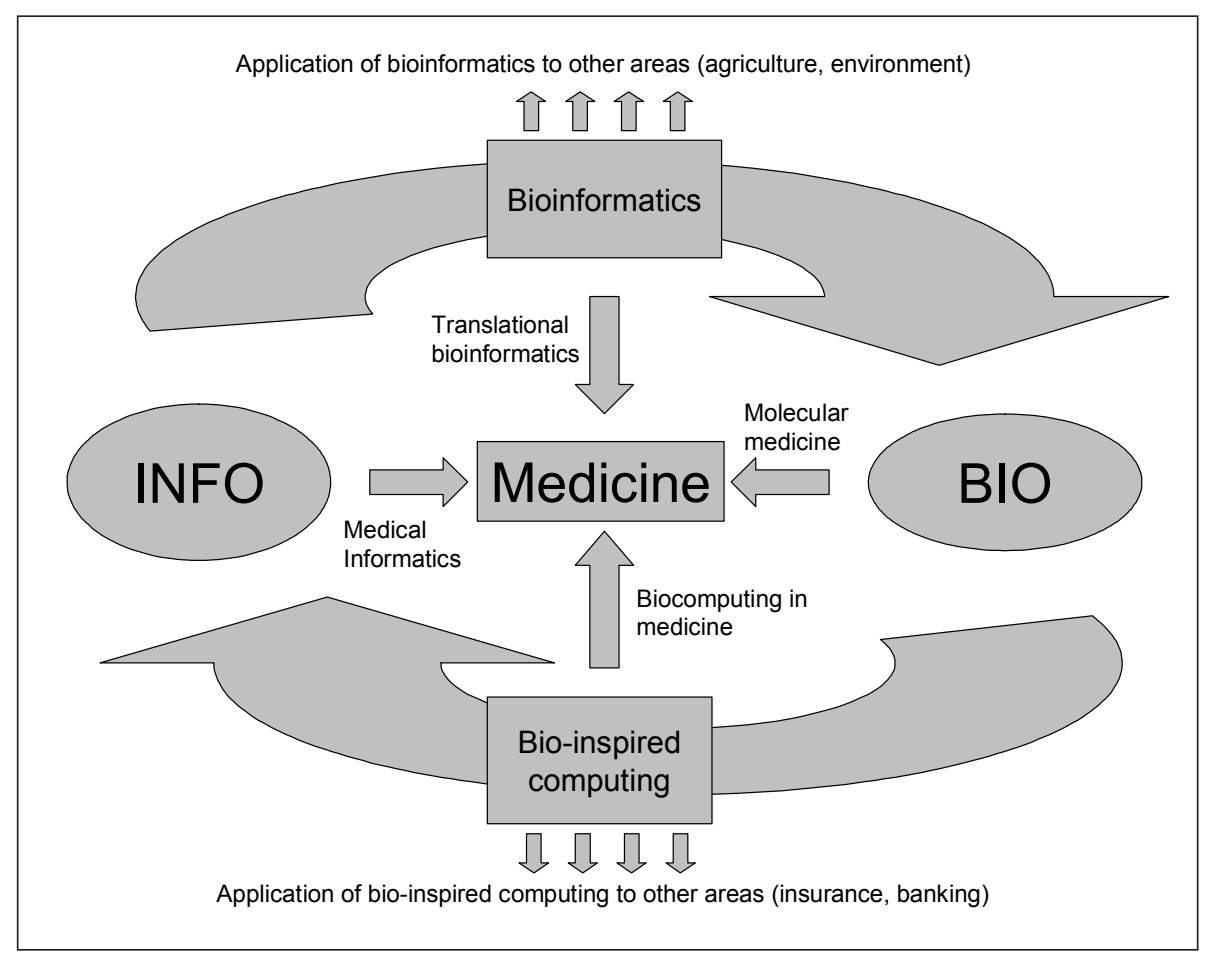

Fig. 2 Bioinformatics and bio-inspired computing resulting from the convergence of BIO and INFO technologies have already been successfully applied in medicine 
Table 2 The BIO-INFO Convergence. Inspiring principles and main developments

\begin{tabular}{|c|c|c|}
\hline & INFO $\rightarrow$ BIO & $\mathrm{BIO} \rightarrow \mathrm{INFO}$ \\
\hline $\begin{array}{l}\text { Inspiring } \\
\text { principles }\end{array}$ & $\begin{array}{l}\text { Advances in high-throughput laboratory } \\
\text { methods and techniques and needs to } \\
\text { manage exponential growth of data } \\
\text { - New data from the Human Genome } \\
\text { Project and post-genome research } \\
\text { - New laboratory technologies (genomics, } \\
\text { proteomics) } \\
\text { - New projects (Hapmap, Encode, cancer } \\
\text { genome...) }\end{array}$ & $\begin{array}{l}\text { Considering living matter (brain, cell) as an information } \\
\text { processing system characterized by: } \\
\text { - Adaptation - Learning } \\
\text { - Self-organization, self-assembly, self-replication, self- } \\
\text { reproduction } \\
\text { - Self-maintennance through energy and matter } \\
\text { harvesting } \\
\text { - Robustness - Re-organization, redundancy, fault- } \\
\text { tolerance } \\
\text { - Collective behavior - stigmercy } \\
\text { - Distributed control } \\
\text { - Evolvability - optimization } \\
\text { - Dynamical - Efficient resource usage } \\
\text { - Parallelism - High performance }\end{array}$ \\
\hline $\begin{array}{l}\text { Physical systems, } \\
\text { hardware and } \\
\text { devices }\end{array}$ & $\begin{array}{l}\text { - Microarrays } \\
\text { - Biochips } \\
\text { " Labchips } \\
\text { - Robotics } \\
\text { - Biosensors }\end{array}$ & $\begin{array}{l}\text { - Evolvable Hardware and bio-inspired robotics } \\
\text { - Biological motors } \\
\text { - Biosensors and biodevices } \\
\text { - Neural processors } \\
\text { - DNA computing and protein memories }\end{array}$ \\
\hline $\begin{array}{l}\text { Algorithms, } \\
\text { methods, software } \\
\text { and databases }\end{array}$ & $\begin{array}{l}\text { - Sequence analysis and molecular } \\
\text { evolution } \\
\text { - Protein structure prediction } \\
\text { - Gene finding and annotation } \\
\text { - RNAi analysis } \\
\text { - Genomics and proteomics data analysis, } \\
\text { including microarrays } \\
\text { - Cell modelling } \\
\text { - Pathways, Networks\& Systems Biology }\end{array}$ & $\begin{array}{l}\text { - Evolution - Genetic programming and algorithms } \\
\text { - Ecology - Social insects intelligence } \\
\text { - Individuals - virtual creatures, artificial life } \\
\text { - Organs - Neurocomputing, artificial neural nets } \\
\text { - System - Immunocomputing } \\
\text { - Cell (Cell and membrane computing, embryonics, P- } \\
\text { systems, computing with bacteria) } \\
\text { - Molecules - DNA computing } \\
\text { - Atoms - Quantum computing }\end{array}$ \\
\hline $\begin{array}{l}\text { Examples of } \\
\text { application in } \\
\text { medicine }\end{array}$ & $\begin{array}{l}\text { - Translational Bioinformatics, including the } \\
\text { Virtual Physiological Human [20] }\end{array}$ & $\begin{array}{l}\text { - Arrificial neural nets for medical diagnosis or genetic } \\
\text { analysis [21] } \\
\text { - Genetic programming for cancer microarray data } \\
\text { analysis [22] }\end{array}$ \\
\hline
\end{tabular}

This table provides the ideas that spurred the development of both the physical (hardware, devices) and logical (methods, programs and algorithms) systems and several examples of their application in medicine.

\subsection{Info-Nano Convergence}

A recent "Workshop on Nanoinformatics Strategies" [23], supported by the National Science Foundation, was held in Arlington, Virginia in 2007. Since that time, the US National Institutes of Health [24] and the US National Cancer Institute [25] have funded initia-
Its main outcome will be the identification of needs and the discussion of future challenges and priorities for Biomedical Informatics in terms of information processing in nanomedicine and regenerative medicine [29]. In the analysis carried out for ACTION Grid, the different partners have emphasized future possibilities for Medical Nanoinformatics, mainly considering an engineering perspective, with different applications such as, for instance: data and knowledge bases of nanoparticles (and their models and biological interactions) [30], research on interoperability (web technologies, middleware and Grid, ontology-based integration), data and text mining, standards, confidentiality, patient safety and others. For instance, within ACTION Grid, researchers have developed a method for the automatic creation of an index of Medical Nanoinformatics resources [31], which had been previously focused on Bioinformatics. This inventory is a collection of tools, databases and services, automatically extracted from a set of scientific documents, by means of text mining techniques, describing resources retrieved from bibliographic databases such as Medline or the ISI Web of Knowledge. Each of these documents is analyzed and processed to extract relevant information using an original text mining approach. This information includes key data from the different informatics tools, nanoparticles and related components. Once the information is retrieved, it is stored following a domain ontology or taxonomy so the information can be accessed by external users.

Nanotechnology is also opening up new perspectives to the computer manufacturing industry. As the existing technology is rapidly reaching physical limits (Moore's Law), nanocomputing, nanoelectronics and nanophotonics appear as potential alternatives for new architectures and designs for the next generations of computers that will surely be also applied to the computational analysis of biomedical problems. 


\subsection{Info-Cogno Convergence}

The study of the human brain represents probably the most challenging scientific task for the next decades. Achievements in this area are expected to contribute to improve the prevention, diagnosis or treatment of highly prevalent nervous system disorders. Neuroscientists are already using new imaging and laboratory analysis methods to investigate the brain at the increasingly higher levels of detail, and these studies are generating a deluge of multimodal, complex and heterogeneous data that need to be processed and analyzed [32]. This research has fueled enormous interest in neuroinformatics, which has been defined as the merging of information science with the neurosciences [33]. In July 2005, researchers from the École Polytechnique Fédérale de Lausanne and IBM announced a new research initiative -a project to create a biologically accurate, functional model of the brain using the IBM's Blue Gene supercomputer. This project represents the first comprehensive attempt to reverse-engineer the mammalian brain, designed to understand brain function and dysfunction through detailed simulations [34]. The term Human Cognome project has been proposed in such a context as a big-science project that aims to chart the structure and function of the human mind [35].

Reciprocally, new computer architectures and systems are being developed that benefit from what it is already known about natural cognition (i.e: neurocomputing software inspired by neural architectures). Cognitive science is the theoretical framework within which the science of brain function and thinking is developed.

Medical applications consist of: new computing paradigms for medical information processing problems (such as, for instance, the next generation of decision support and artificial intelligence systems) and information systems that could help supplement certain cognitive processes through the use of hybrid neural interfaces, sen- sors or pharmacological interference with the nervous system.

\subsection{Info-Bio-Nano Convergence}

The advance of miniaturization technologies has facilitated the study of biological matter at scales not previously feasible [36]. The possibility of visualizing biological molecules at the nano $\left(10^{-9}\right.$ metres) length scale opens the door to the development of artificial systems that interact with living matter, significantly contributing to progress in several medical fields [37]. Nanotools are being developed and applied to the study of biological material, an approach that what we could refer to as the "nanoscope". This allows scientists to visualize and manipulate living systems at the smallest level [38]. Some examples of these nanotechnological tools are quantum dots, used to label molecules or bionanosensors that use biological molecules as detection material [39]. Biology can also be taken as a model for building artificial constructs $[40,41]$. In this case it is possible to use viruses for manufacturing nanoparticles, or adapt ribosomes to function as molecular switches. Examples of Nano-Bio-Info convergence with applications in Medicine are: i) intelligent drug delivery systems [42], ii) molecular imaging [43] and iii) biosensors [44].

\section{The Relevance of the Nano-Bio-Info-Cogno (NBIC) Convergence to Health}

As a report by Ireland Engineers [45] states: "A Picture of Health 2030 is one that will be shaped largely by a convergence of diverse technologies, and this calls for new interdisciplinary structures and approaches". A broad range of applications of converging technologies are foreseen in healthcare and biomedical research [46-52]. Miniaturiza- tion of devices and building up structures and nano-devices at the molecular level will facilitate regenerative medicine [53]. The pharmaceutical industry is assessing the applicability of these new trends in the search for a more efficient drug discovery pipeline, reformulation of drugs to achieve less toxicity and design of more personalized drug prescription regimes. The following should not be considered as an exhaustive list, but as a brief description of several of these expected advances:

- RESEARCH: New artificial organs will facilitate the modeling of toxicological effects of drugs or chemicals. Next generation ultra-fast DNA sequencers based on nanospheres or nanopores are expected to read a complete individual genome in a few days at affordable cost.

- POINT OF CARE TESTING: "labon-a-chip" technologies will provide fast screening and early disease detection. Nanoarrays for diagnosis at the point-of care will require less time to produce results and will have to be coupled with decision support systems [54].

- SENSORS: New miniaturized sensors will be able to detect biomarkers and environmental pollutants [55]. Nano-based body sensors embedded in clothes will monitor physiological properties, recording them or even transmitting them online to clinicians for patient monitoring.

- IMAGING: Molecular imaging methods will detect patterns of gene expression or other biological processes "in vivo" to facilitate early disease detection.

- THERAPY: Targeted and localized drug delivery systems will present fewer secondary toxicological effects, and will be capable of assessing and analyzing their effect and react and communicate with systems outside the body.

- PROSTHESIS: New biocompatible materials in orthopedics, and intelligent prostheses that will be able to interact with brain signals from patients and transmit sensory information. 
Implantable artificial organs will enhance or substitute natural ones.

- REGENERATIVE MEDICINE: Results of tissue engineering will enable the replacement of damaged body parts, and genetic and cellular therapies will help to recover from diminished or lost biological function.

- SURGERY: Biocompatible microrobots inside the body could perform various functions for in vivo medical use.

Biochips represent a good example of converging technologies. The first systems arose from the convergence of information technologies (microelectronics) and biotechnology when photolithographic methods were used for in-situ synthesis of small DNA molecules on the surface of a glass slide [56]. They have been extensively used in biomedical research, but they still face limitations in order to be routinely used in clinical practice. Some of these barriers could be overcome through new developments coming from other converging disciplines. Cognitive models of medical reasoning could add an intelligent layer to these systems, making them more suitable to be applied in clinical settings. Furthermore, miniaturization promises to place these devices closer to the point-of-care, paving the way to a new generation of portable and intelligent molecular analysis devices. Lastly, these analytical devices could be applied to perform genetic analyses (gene expression) in the context of neuroscience. These ideas are represented in Figure 3.

\section{Positioning $\mathrm{BMI}$ in the Context of NBIC}

Although the full promises and potentialities of the NBIC convergence and their application in medicine are far from being achieved, there are already significant examples of convergence successfully applied in medicine. In such a context BMI will surely play an impor- tant role. Particularly, we would like to emphasize its possible active participation in the development of the different "nano" field, which promises to deliver breakthroughs in all areas of medicine, including research, diagnosis, monitoring, therapy and prognosis. This aspect is illustrated in Figure 4.
In the 1990s, Genomics research was boosted by the development of multiple bioinformatics tools, anticipating by years the completion of research projects such as the Human Genome Project. While Bioinformatics is usually applied in the context of analyzing DNA sequences and other biomolecular

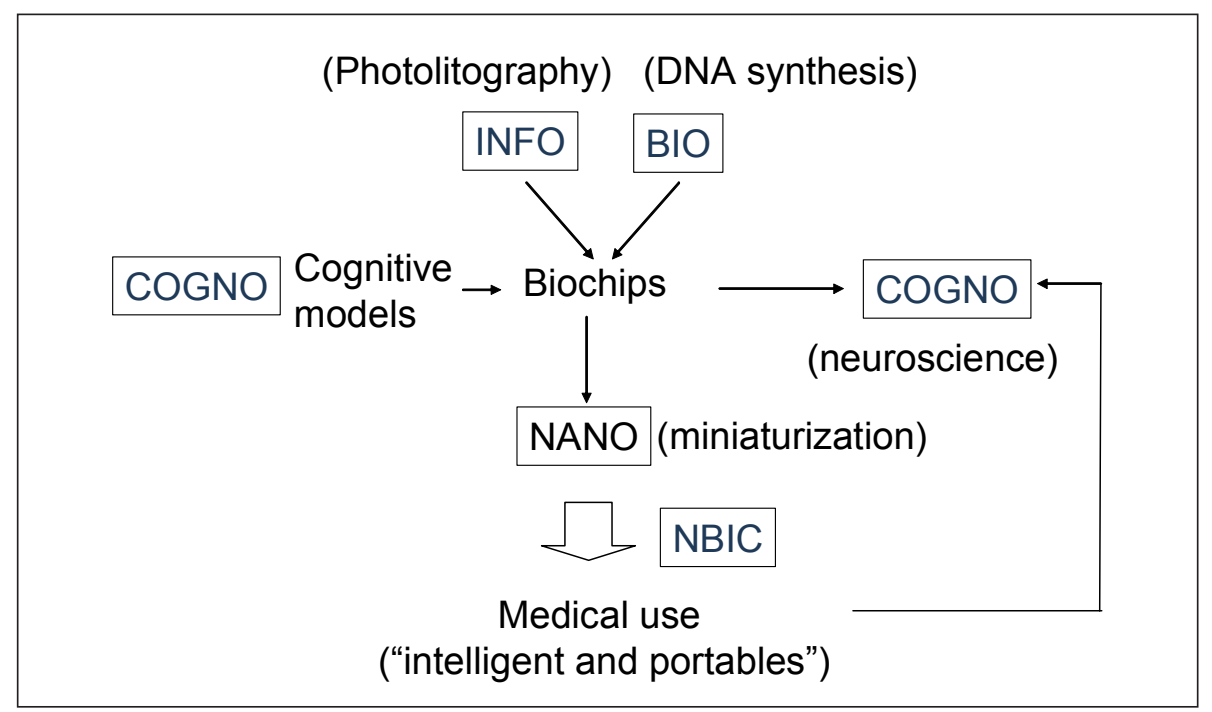

Fig. 3 Convergence of technologies around microarrays and their medical use

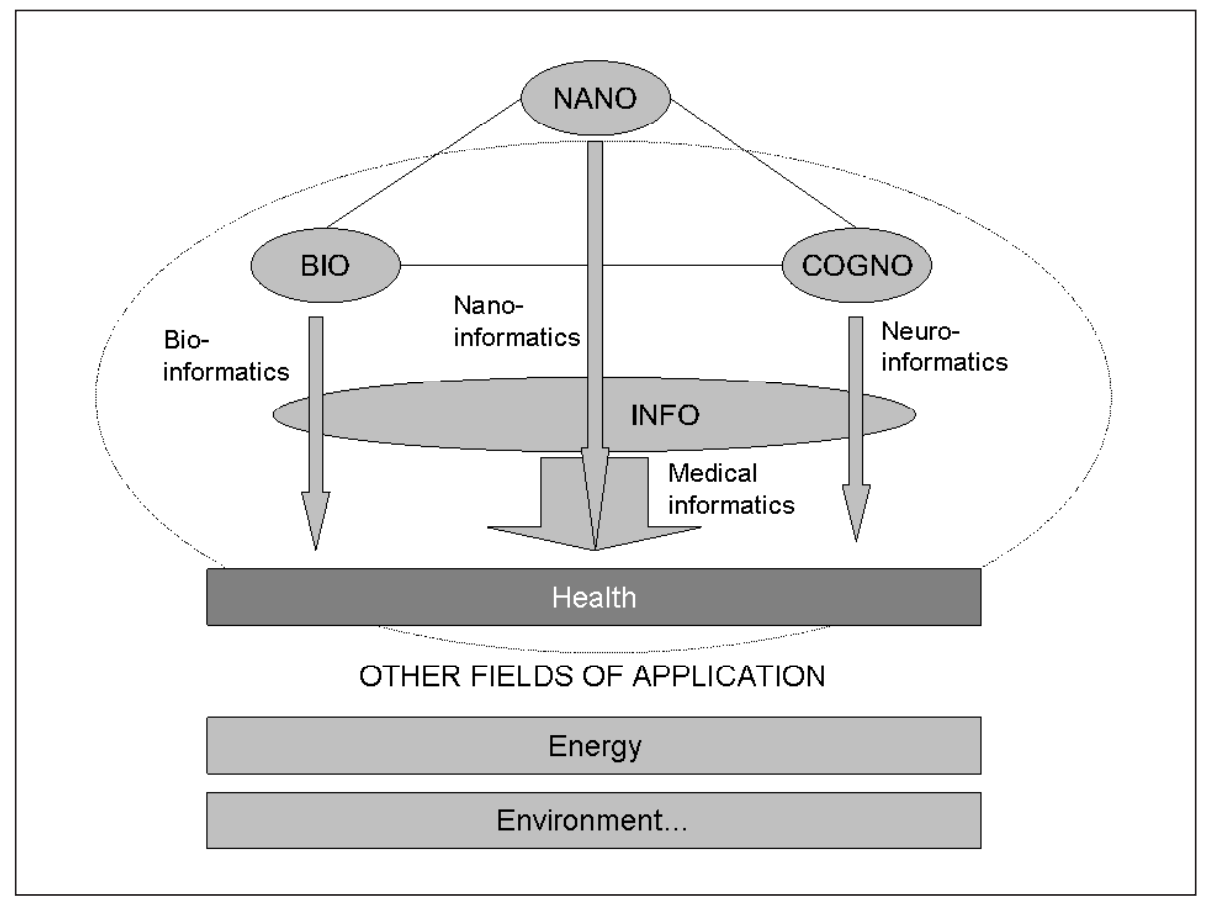

Fig. 4 The ellipse represents the area that biomedical informatics covers regarding the NBIC tetrahedron and its application in the health sector. Several subspeciallies of BMl are mapped in this context. 
data, Medical Nanoinformatics is applied for characterizing nanoparticles and materials. This information must be represented in electronic medical records and will have to be used in future clinical routine.

Like for all new areas with great scientific possibilities and challenges ahead, some -or many- questions arise. For instance, those related to actual industrial applications in the short or mid term, patient safety issues, political and social implications, etc. In fact, one may wonder whether everything that is proposed here under this umbrella of converging technologies is new. Such an interchange between disciplines already began with cybernetics and allied areas, where an amazing group of scientists from various fields gathered to study differences and similarities between animals and machines, leading to outstanding achievements -e.g., mathematical models of homeostasis, information and feedback processes in the nervous system, new minirrobots, mathematically inspired models of neurons and many others. Such exchange between info, bio and cogno ideas and models was already proposed in the 1950s, although scientific knowledge could not provide the materials and methods that were needed. And, in fact, $40+$ years later, the new proposals still seem far from what is actually available on our scientific shelves. Thus, similarly to what happened to cybernetics it is possible that such a long term vision might not be supported by public and private funding, where results are rarely delayed for such a long time.

Changes are being produced so rapidly that, even though the area of genomic medicine has been only recently proposed and many are looking to the next decade for its full deployment, a new area, nanomedicine, is promising greater challenges and advances in both medical science and technology. It seems, that both areas (genomic and nanomedicine) and strategies for supporting them, are complementary, but funding for scientific research is being reduced in many countries and areas and competition may increase. In any case, an emphasis on basic scientific research should provide the concrete contributions needed to support a more ambitious, long term research plan. In both basic and applied scientific research in genomic and nanomedicine, the role of BMI will be decisive to advance these areas. A possible model is provided in Figure 5.

\section{Conclusion}

It is widely recognized that innovation and research breakthroughs frequently occur at the intersections between disciplines [57, 58]. From very diverse perspectives it is being claimed that we are witnessing a new age of science and technology [59]. The convergence is expected to contribute to closing several loops between aspects which up to now have been clearly independent, and seldom interconnected: (artificial vs. natural, man vs. machine, living vs. inert, mind vs. body, nano vs. macro, science vs. technology, thought vs. artificial intelligence, medical devices vs. drugs, diagnostics vs. therapeutics or discovery vs. construction) [60].

The inclusion of biological science and biotechnology issues within the realm of medical informatics has given rise to biomedical informatics. Similarly, if biomedical informatics is to play an important role in the next wave of converging NBIC technologies, special attention will have to be paid to education [61]. Some activities that could be undertaken are: -including modules on nanotechnology and converging technologies in educational programs, -setting up partnerships with research groups with experience in nanotech and cognitive science, -encouraging students to gain experience working in such interdisciplinary fields, in addition to acquiring disciplinary depth [62], -identifying precursor NBIC projects and promoting problemsolving oriented research, -organizing joint scientific events, -opening up journals to interdisciplinary articles, -devoting considerable effort to ethical, legal and social issues, including social scientists or humanists in the projects, -setting up observatories, -involving industry and user groups, -developing

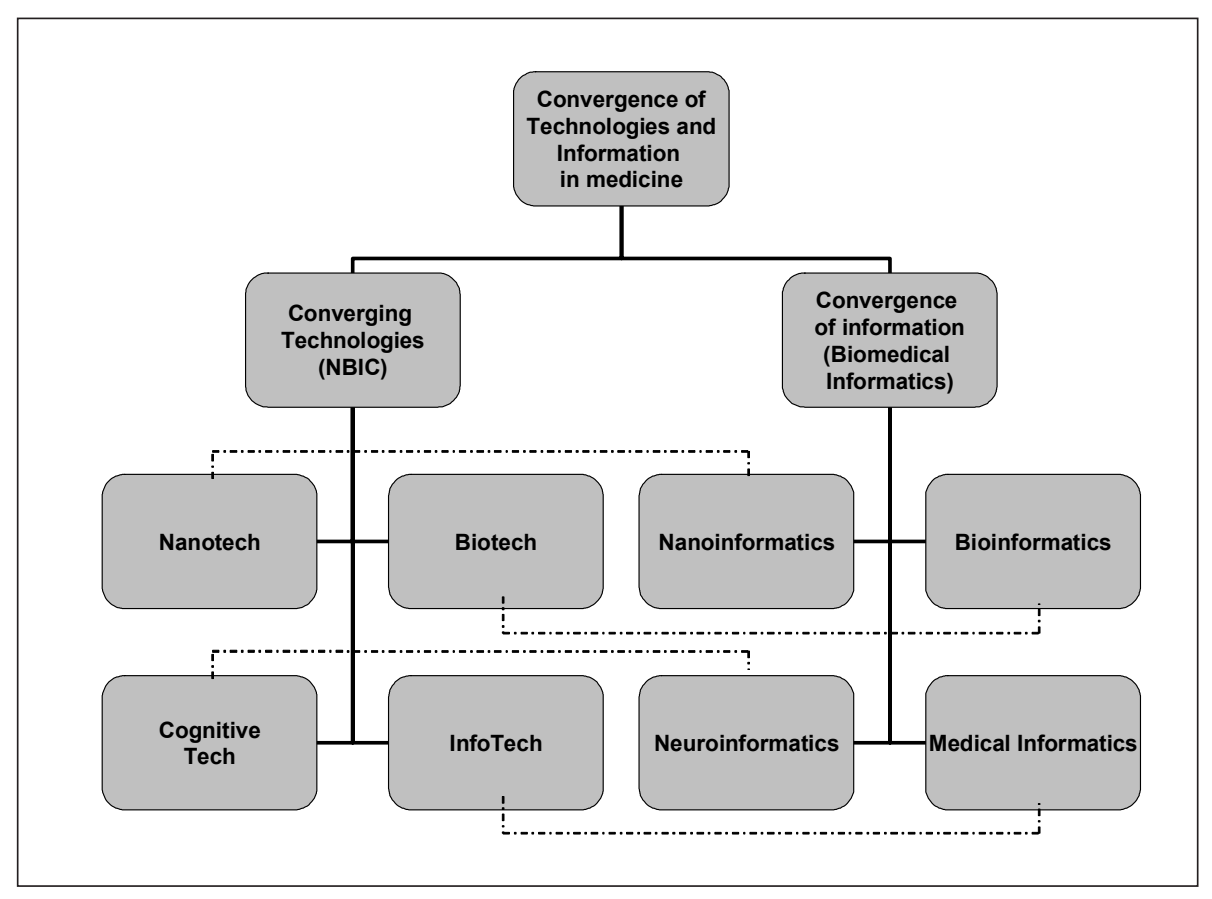

Fig. 5 A model for the convergence of technologies and information in medicine 
material for disseminating advances to the general public.

Finally, as the Joint Commission states: "As health information technology (HIT) and "converging technologies" ... are increasingly adopted by health care organizations users must be mindful of the safety risks and preventable adverse events that these implementations can create or perpetuate" [63]. In other words, actions will have to be taken to avoid harmful effects related to the implementation and use of converging technologies.

The intersections of BMI with disciplines such as nanotechnology and cognitive science provide new directions, but also present challenges for integration and training of future scientists in such broad areas.

\section{Acknowledgments}

This research was supported in part by the European Commission (ACTION-Grid project), the Ministry of Science and Innovation of Spain (COMBIOMED network and OntoMineBase and NanoSost projects) and the Comunidad de Madrid. We gratefully acknowledge Isabel Hermosilla-Gimeno and Guillermo LopezCampos for their comments and help in reviewing the manuscript.

\section{References}

1. Toffler, A. The Third Wave. New York: Bantam; 1980).

2. Gingrich, N. The age of transitions. In Roco M, Bainbridge WS, editors. Social implications of nanoscience and technology. NSET workshop report. Dordrecht, Boston, London: Kluwer; 2001.

3. Anton PS, Silberglitt R, Schneider J. The global technology revolution. Bio/Nano/Materials trends and their synergies with information technology by 2015. Santa Monica, CA: RAND National Defense Research Institute (NDRI); 2001.

4. Roco MC, Bainbridge WS, editors. Converging technologies for improving human performance. Nanotechnology, biotechnology, information technology and cognitive science. Arlington, Virginia: National Science Foundation (NSF) / Department of Commerce (DOC); 2002.

5. R. Bouchard. Bio-Systemics Synthesis: Science and Technology Foresight Pilot Project. Technical report, Canadian Research Council, Ottawa; 2003.

6. Nordmann A. (Rapp) and the High Level Expert Group - Foresighting the New Technology Wave. Report "Converging Technologies - Shaping the Future of European Societies"; 2004.
7. EC Project Knowledge Politics and New Converging Technologies; A Social Science Perspective. Available from: http://www.convergingtechnologies.org/index.html. June 2009.

8. European Parliament. Directorate-General for Internal Policies of the Union. ETAG European Technology Assessment Group. Technology Assessment on Converging Technologies. IP/A/STOA/SC/2005183. October; 2006.

9. Aguiló J. et al., Tecnologías Convergentes NBIC, Situación y Perspectiva. (2005), CBN-IBM, IIBB, IIIA, CSIC Barcelona Available from: http:// nbic.org.es/institute/downloads-eu/NBIC-2005.pdf. June 2009.

10. Converging Technologies Forum 2007. Barcelona, Spain. Available from: http://nbic.org.es/forum2007/. June 2009.

11. Martin-Sanchez F, Lopez-Campos G. Convergencia de Tecnologías: nuevas oportunidades para el avance de la Informática y de las Ciencias Biomédicas. Revista e-salud (2006) Available from: http:// www.RevistaeSalud.com, Vol 2, No 6. June 2009.

12. Kodama, Fumio. Technology fusion and the new R\&D. Harvard Business Review 1992; July- August:70-8.

13. Schummer J. Interdisciplinary Issues in Nanoscale Research. In: Baird D, Nordmann A, Schummer J, editors. Discovering the Nanoscale, Amsterdam: IOS Press; 2004.

14. Andler D, Barthelmé S, Beckert B, Blümel, C, Coenen, C, Fleischer T, et al. Converging Technologies and their impact on the Social Sciences and Humanities. Final report of the CONTECS project. May (2008). Available from: http:// www.contecs. fraunhofer.de. June 2009.

15. Roska T, Werblin FS, Pin JE, editors. European Commission -US National Science Foundation Strategic Research Workshop "BIONICS - Bio-inspired Information Technologies". Report and Recommendations. Brussels; 2001.

16. http://14dec2001.ramit.be/ June, 2009.

17. Martin-Sanchez F, Iakovidis I, Norager S, Maojo V, de Groen P, Van der Lei J, et al. Synergy between medical informatics and bioinformatics: facilitating genomic medicine for future health care. J Biomed Inform 2004;37(1):30-42.

18. Meeting Report. "Extending the scope of ICT at the crossroads with life sciences". An European Commission IST Workshop contributing to future research priorities October, Brussels; 2004

19. Martin-Sanchez F, editor. Bio-inspired computing. Final report of the European Project Beyond-TheHorizon. Thematic Group 4. Available from: ftp:// ftp.cordis.europa.eu/pub/ist/docs/fet/strat-4.pdf. June 2009.

20. Kuhn KA, Knoll A, Mewes HW, Schwaiger M, Bode A, Broy M, et al. Informatics and medicinefrom molecules to populations. Methods Inf Med 2008;47(4):283-95.

21. Spicker JS, Wikman F, Lu ML, Cordon-Cardo C, Workman C, ØRntoft TF, et al. Neural network predicts sequence of TP53 gene based on DNA chip. Bioinformatics 2002;18;8:1133-4.

22. Liu KH, Xu CG. A genetic programming-based approach to the classification of multiclass microarray datasets. Bioinformatics 2009; 25;3:331-7.
23. Workshop on Nanoinformatics Strategies. Available from: http://128.119.56.118/ nnn01/ Workshop.html. June 2009.

24. Covitz P. caBIG ${ }^{\mathrm{TM}}$ and Nanotechnology Informatics. Available from: http://128.119.56.118/ $\sim$ nnn01/NewFiles/04_Covitz_caBIG.pdf June 2009.

25. Baker NA, Guccione S, Paik D, Pappu RV, Patri A, Rubin D, et al. Nanotechnology Informatics White Paper, caBIG Integrative Cancer Research Nanotechnology Working Group, February; 2009.

26. ACTION-Grid project website. http://www.actiongrid.eu. June 2009 .

27. Lopez-Alonso V, Hermosilla-Gimeno I, LopezCampos G, Maojo V, Martin-Sanchez F. Action GRID: assessing the impact of Nanotechnology on Biomedical Informatics. AMIA Annu Symp Proc 2008 Nov 6:1046.

28. Maojo V, Kulikowski CA. Reflections on Biomedical Informatics: From Cybernetics to Genomic Medicine and Nanomedicine. Stud Health Technol Inform 2006;124:19-24.

29. Altman RB, Balling R, Brinkley JF, Coiera E, Consorti F, Dhansay MA, et al. Commentaries on "Informatics and medicine: from molecules to populations". Methods Inf Med 2008;47(4):296-317.

30. Martin-Sanchez F, Lopez-Alonso V, HermosillaGimeno I, Lopez-Campos G. A Primer in Knowledge Management for Nanoinformatics in Medicine. In Proceedings of the KES Conference 2008. Zagreb, Croatia.

31. Chiesa S, García-Remesal M, de la Calle G, de la Iglesia D, Bankauskaite V, Maojo, V. Building an Index of Nanomedical Resources: an Automatic Approach based on Text Mining. In proceedings of the KES 2008. Zagreb, Croatia.

32. Grillner, S. et al. Integrative Neuroscience: Linking levels of analyses. Current Opinion in Biotechnology 2005;15: 614-21.

33. Report on Neuroinformatics from The Global Science Forum Neuroinformatics Working Group of the Organisation for Economic Co-operation and Development June; 2002.

34. http://bluebrain.epfl.ch/. June 2009

35. Horn, RE. Visual Language and Converging Technologies in the Next 10-15 Years (and Beyond) A paper prepared for the National Science Foundation Conference on Converging Technologies (Nano-BioInfo-Cogno) for Improving Human Performance. Dec. 3-4, 2001.

36. Cachau RE, Gonzalez-Nilo FD, Ventura, ON, Fritts MJ. In-silico nano-biodesign. A new frontier in computational biology. Current Topics in Medicinal Chemistry 2007;7(15):1537-40.

37. Roco MC. Nanotechnology: convergence with modern biology and medicine. Current Opinion in Biotechnology 2002;14(3):337-46.

38. Chen JM, Ho CM. Path to bio-nano-information fusion. Ann NY Acad Sci 2006;1093: 123-42.

39. Lymberis A. Converging Micro-Nano-Bio-Information \& Communication Technologies Towards Integrated Systems: the Contribution of the EU Information Society Technologies Program. Engineering in Medicine and Biology Society. EMBS 2007. 29th Annual International Conference of the IEEE 22-26 Aug 2007. p. 6445

40. Goodsell, D. Bionanotechnology: Lessons from Nature. Wiley; 2004.

41. Kulkarni RP. Nano-Bio-Genesis: Tracing the rise 
of nanotechnology and nanobiotechnology as 'big science'. J Biomed Discov Collab 2007:2:3.

42. Jain KK. The role of nanobiotechnology in drug discovery. Drug Discov Today 2005;10 (21):1435-42.

43. Weissleder R. Molecular imaging in cancer. Science 2006:312(5777):1168-71.

44. Politz J, Pombo A. Genomics meets nanoscience: probing genes and the cell nucleus at 10-9 meters. Genome Biology 2002;3(3):4007.1-4007.3

45. Caffrey P (Chair) et al. Taskforce convened by Engineers Ireland and the Irish Academy of Engineering. A Picture of Health in 2030. Engineering the Future of Health and Medicine; 2006 Available from: http://www.emgineersireland.ie.

46. Freitas RA. What is nanomedicine? Nanomed Nanotechnol. Biol Med 2005;1:2e9

47. Kewal KJ. The Handbook of Nanomedicine. Totowa, NJ: Humana Press; 2008.

48. Kubik T, Bogunia-Kubik K, Sugisaka M. Nanotechnology on duty in medical applications. Curr Pharm Biotechnol 2005;6:17-33.

49. European Technology Platform on NanoMedicine Nanotechnology for Health: Vision Paper and Basis for a Strategic Research Agenda for NanoMedicine; 2005. Available from: http://cordis europa.eu/nanotechnology/nanomedicine.htm

50. European Science Fundation - European Medical Research Councils (EMRC). Forward look on Nanomedicine; 2005.

51. Pritchard J, Binks P, Critchley M, Irving B. Nanotechnology: the next wave of commercial de- velopment for health and medical devices-an Australian story. Nanomed 2007;2(2):255-60.

52. Williams D. Medical nanotechnology: how small can we go? Med Device Technol 2002 Apr;13(3):7-9.

53. Hatton P, Wallace WA, Lloyd-Evans M, Silcock D, Lewis A, Jackson A. DTI Global Watch Mission Report-The impact of converging technologies on medical devices - a mission to the USA - October 2005. Published by Pera on behalf of the DTI. Crown; 2006.

54. Martin-Sanchez F, Maojo V, Pazos A, Dorado J, Guerrero, A. Converging Technologies for the Improvement of Clinical Diagnosis and Management at the Point of Care (POC). Proceedings of the Workshop held at Converging Technologies Forum, 2007. Barcelona: CSIC-UAM, 2007.

55. Yager P, Edwards T, Fu E, Helton K, Nelson K, Tam MR, et al. Microfluidic diagnostic technologies for global public health. Nature 2006; 442(7101):412-8.

56. Fodor SP, Read JL, Pirrung MC, Stryer L, Lu AT, Solas D. Light-Directed, Spatially Addressable Parallel Chemical Synthesis. Science 1991;251:767-73.

57. Giorgi L, Luce J, editors. Converging Science and Technologies: Research Trajectories and Institutional Settings, Special Issue of Innovation; The European Journal of Social Science Research 2007;20(4).

58. Luce J, Giorgi L, editors. Knowledge Politics and Converging Technologies, Special Issue of Innovation; the European Journal of Social Science Re- search 2009;22(1).

59. Fuller S. Knowledge NBIC. Knowledge Politics and new Converging Technologies: A Social Science Perspective. http://www.convergingtechnologies.org

60. Schicktanz S. Why the way we consider the body matters - Reflections on four bioethical perspectives on the human body. Philos Ethics Humanit Med 2007;2:30. Published online 2007 December 4. doi: 10.1186/1747-5341-2-30.

61. Roco MC. Converging science and technology at the nanoscale: opportunities for education and training. Nat Biotechnol 2003 Oct;21(10):1247-9.

62. Gorman ME. Collaborating on convergent technologies: education and practice. Ann N Y Acad Sci 2004; 1013:25-37.

63. The Joint Commission. Sentinel Event Alert. Safely implementing health information and converging technologies. 2008;42 December 11.

Correspondence to:

Fernando Martin-Sanchez

Medical Bioinformatics Dept.

Institute of Health Carlos III

Ministry of Science and Innovation

Majadahonda 28220

Madrid, Spain

Fax: +34 918223219

E-mail: fms@isciii.es 